\title{
Analysis of DG Influences on System Losses in Distribution Network
}

\author{
Shipeng Du, Qianzhi Shao and Gang Wang \\ Shenyang Institute of Engineering, Shenyang, China \\ * Corresponding author: sensorbeh@163.com
}

\begin{abstract}
Nowadays distributed generation is often associated with the distribution network. Distributed power supply will have an important impact on the system network loss when it connects to distribution network. Change rate of the network loss and distribution rate of the network loss is mentioned after introducing the types and the grid-connected modes of distributed power supply. Theoretical analysis of distributed power supply influences on system net losses in distribution network is done by the way of treating distributed power supply as the special load which can output active power. The result shows the relation of distributed power supply influences on system losses with its capacity connected to the grid, its location and its operation mode. This provides a theoretical basis for grid-connected of the actual distributed power supply.
\end{abstract}

Keywords: distributed generation, net loss, distribution network, distributed power supply.

\section{Introduction}

At present, China's power supply systems are centralized large-capacity power supply system with the main feature of large units, large power grid and the high voltage. But with the development of the times, large-capacity power supply system is gradually showing its own defects and shortcomings.

1) The power supply systems in remote areas always have the problems in high cost of construction and long period of time. This kind of situation results in failing to be the ideal power supply;

2) The traditional power supply can not adapt to load changes quickly. For example, the rapid growth of heating equipment in winter will lead to short-term shortage in electricity supply. This kind of load is a short-term load, so it is unrealistic to construct the generation and transmission facilities exclusively for it. At the same time, diversification of modern appliances makes the rate of power load change increase, resulting in the decrease of the original power grid use rate;

3) For large interconnected grid system, local accident is so easy to spread that it makes a serious threat to the security and stability of the system;

4) Large grid system has a large demand for resource and makes great impact on the environment. In the current global energy shortage and serious environmental pollution, it become an important direction of power system development that how to use the energy effectively and protect the environment [1].

Hence the foreign experts put forward new operation mode which combines the distributed generation with distribution network to improve the flexibility, reliability and security of power system operation. 


\section{The Advantages and the Types of Distributed Generation}

\subsection{The Advantages of Distributed Generation}

Distributed generation is a new type of power generation compared traditional centralized power supply. Distributed generation is located in the vicinity of the user with small capacity (from several $\mathrm{kW}$ to fifty $\mathrm{MW}$ ) and decentralized way. It can not only separate from the public power grid to provide electricity directly for a small number of users, but also be connected to the distribution networks to provide power to users together [2]. Distributed generation has the characteristics of generating and consuming electricity at the same place so that it can improve power supply reliability and power quality. Generally speaking, the switching and generating capacity size of distributed generation are not under the control of large power grid scheduling.

With the dual pressures of the environment and resources increasing, advantages of conventional power generation mode are also relatively reduced. In recent year, we can find the following application advantages of distributed generation connected to power system from the demand of the whole society to electric power system:

1) It can save a lot of cost for transmission and distribution expanding capacity through installing distributed power generation device in the remote areas and the places whose load is suddenly growth;

2) It can reduce system losses in distribution network effectively through making rational optimization to the power network with distributed power supply.

3) Distributed power supply can be used as an alternate to provide power for important users instead of power system when the power system breaks off. This can reduce losses caused by power cut [3].

4) Distributed generation can improve fuel efficiency and reduce pollution. For example, it can reclaim the heat generated by the power generation process through building cogeneration plant. Then deliver the heat and electricity to the user together.

5) Distributed generation will make a certain effect on the electric power market. Distributed generation groups allow to be installed by users themselves. When the public grid is overloaded, the owner of distributed generation can sell electricity to the grid company. This not only help ease the pressure on the public grid load but also help suppress the price of electricity, so as to achieve better economic;

6) Distributed generation has the characters of small generation capacity, small volume, convenient flexible installation and short investment period. This reduces the installation cost and investment risk.

\subsection{The Types of Distributed Generation}

Classification of distributed generation is different in different areas. Now the popular way is according to the type of distributed generation technology.

Distributed generation can be classified into two categories by the power energy. One class of distributed generations use renewable energy to generate electricity including solar photovoltaic, wind energy, geothermal energy, ocean energy and other forms of generation. Another is the use of non-renewable energy DG, including internal combustion engines, cogeneration, fuel motivation, micro gas turbines, fuel cells and other forms of electricity generation.

Distributed generation can also be classified into two categories by grid interface technology. One class of distributed generations can be connected with the electric power system directly because of using rotary generator to produce electricity. Such as small gas turbine power generation, hydroelectric power generation, solar power generation, etc. Another is connected with the electric power system indirectly through the inverter converting direct current to alternating current or producing a high-frequency alternating current [4]. 
Table 1. The Types of Distributed Generation

\begin{tabular}{|c|c|c|c|c|c|c|}
\hline Technology & Technolog & $\begin{array}{c}\text { Grid } \\
\text { interface }\end{array}$ & Output & \multicolumn{3}{|c|}{ Scale type } \\
\hline $\begin{array}{l}\text { Hydroelectri } \\
\text { c power }\end{array}$ & $\begin{array}{l}\text { renewable } \\
\text { energy }\end{array}$ & $\begin{array}{l}\text { connect } \\
\text { directly }\end{array}$ & $\mathrm{AC}$ & large & $\begin{array}{l}\text { medi } \\
\text { um }\end{array}$ & \\
\hline $\begin{array}{l}\text { Wind power } \\
\text { generation }\end{array}$ & $\begin{array}{l}\text { renewable } \\
\text { energy }\end{array}$ & inverter & $\mathrm{AC}$ & large & $\begin{array}{l}\text { medi } \\
\text { um }\end{array}$ & small \\
\hline Solar power & $\begin{array}{l}\text { renewable } \\
\text { energy }\end{array}$ & inverter & $\mathrm{DC}$ & large & $\begin{array}{l}\text { medi } \\
\text { um }\end{array}$ & small \\
\hline $\begin{array}{l}\text { Geothermal } \\
\text { power }\end{array}$ & $\begin{array}{l}\text { renewable } \\
\text { energy }\end{array}$ & $\begin{array}{l}\text { connect } \\
\text { directly }\end{array}$ & $\mathrm{AC}$ & large & $\begin{array}{l}\text { medi } \\
\text { um }\end{array}$ & \\
\hline Fuel cell & $\begin{array}{c}\text { fossil } \\
\text { fuels/ } \\
\text { renewable } \\
\text { energy }\end{array}$ & inverter & $\mathrm{DC}$ & large & $\begin{array}{l}\text { medi } \\
\text { um }\end{array}$ & small \\
\hline $\begin{array}{l}\text { Small gas } \\
\text { turbine }\end{array}$ & $\begin{array}{c}\text { fossil } \\
\text { fuels/ } \\
\text { renewable } \\
\text { energy }\end{array}$ & $\begin{array}{l}\text { connect } \\
\text { directly }\end{array}$ & $\mathrm{AC}$ & large & & \\
\hline $\begin{array}{l}\text { Micro } \\
\text { turbine }\end{array}$ & $\begin{array}{c}\text { fossil } \\
\text { fuels/ } \\
\text { renewable } \\
\text { energy }\end{array}$ & inverter & $\mathrm{AC}$ & & $\begin{array}{l}\text { medi } \\
\text { um }\end{array}$ & small \\
\hline $\begin{array}{l}\text { Biomass } \\
\text { power } \\
\text { generation }\end{array}$ & $\begin{array}{l}\text { renewable } \\
\text { energy }\end{array}$ & $\begin{array}{l}\text { connect } \\
\text { directly }\end{array}$ & $\mathrm{AC}$ & large & $\begin{array}{l}\text { medi } \\
\text { um }\end{array}$ & small \\
\hline
\end{tabular}

\section{The Connection of Distributed Generation to Grid}

\subsection{The Basic Technical Requirements of Distributed Generation Connected To Grid}

Distributed generation connected to the distribution network will affect the operation mode and performance of distribution network. In order to ensure the safe operation of distribution network and the power supply quality of users, the connection of distributed generation to grid must meet the following basic requirements:

1) It must ensure the distribution network qualified that the voltage deviation caused by the connection of distributed generation to grid dose not exceed the allowed range;

2) The normal operation current of distribution equipment does not exceed the rated value and the thermal stability current does not exceed the allowable value [5];

3) Short circuit capacity does not exceed the allowable value of the distribution, such as circuit breaker, cable, etc;

4) The quality of the power produced by distributed generation is qualified. The voltage sag, swell, flicker and harmonic caused by it do not exceed the specified value. 


\subsection{The Operation Mode and Grid Connected Mode of Distributed Power Supply}

Based on the relationship between the distributed generation and distribution network the distributed power usually run in four ways

1) Distributed power supply operates independently to provide power to the users nearby;

2) Distributed power supply operates independently, but there is a switch between it and distributed generation. When the distributed power supply breaks off, its users will be powered by the local distribution network instead;

3) Distributed power supply makes the parallel operation with distribution network while its power generation mainly meets its own electricity demand. It does not supply power to the local distribution network [6];

4) Distributed power supply makes the parallel operation with distribution network and it also supplies power to the local distribution network.

\section{The Impact of Distributed Power Supply to Distribution Network}

The traditional distribution networks are generally radial distribution networks with a single power supply. The power distribution system will change radically when distributed power supply is connected to the traditional distribution network. The distribution network changes from a radial network to a new network with power supplies anywhere and users interconnected. This will make the control and management of the distribution network more complex. Now the distribution automation is also necessary to be reconsidered.

\subsection{The Impact on the Voltage Distribution}

The traditional distribution networks are generally radial distribution networks with a single power supply. Voltage decreases along the feeder power flow when it is under normal operating conditions. If the power of load consumption is constant value and the power system is under the steady-state operation, the access of distributed power supply will reduce the actual transmission power on the line. Some distributed power supplies also issue reactive power to compensate for the line so that the voltage of line load node increases [7].

Active and reactive power of load is not often fixed in actual operation. The changes of line load will make the line voltage change. The closer to the end of the line, the bigger change it is. Active and reactive load changes over time will cause the system voltage fluctuation. This kind of fluctuation is more and bigger toward the end of the line direction. If the load is concentrated at the end of the line, the amount of voltage change will be greater. This kind of situation is generally avoided from happening. After the distributed generation access system, it will increase or decrease the amount of change.

\subsection{The Impact on the Power Quality}

After the distributed generation connected to the distribution network, it will have a negative impact on the system. For example, various disturbances, which have an impact on system, power quality. Its impact is mainly on two aspects of voltage flicker and harmonics.

Distributed generation may cause voltage flicker in the following cases:

1) Large-scale distributed generation system switch;

2) The output of distributed generation suddenly changes;

3) Distributed power generation system and voltage control device of feedback link influence each other. 
The current solution is to require the owner of distributed generation reducing the switching frequency of distributed generation and connecting the distributed generation to the distribution network through the inverter in order to reduce a substantial change in the output of distributed generation [8].

Distributed generation may cause harmonics in the following cases:

1) Distributed power supply itself is a harmonic source;

2) Distributed generation is connected to the distribution network through the inverter based on the power electronic technology.

Distributed generation system incorporated into the distribution network will also bring other dynamic power quality problems such as voltage drop, voltage pulse, momentary power interruptions, etc.

\subsection{The Impact on the System Protection}

It is generally believed that the distribution network has only one power supply so that the fault current of fault point is only provided by the power supply when the line break down. After distributed generation connected to grid, the topological structure of distribution network is changed to be multi-source network. When a failure occurs, distributed power supply also provides fault current to fault point that makes the magnitude and direction of fault current change. This will make original protection devices malfunction or refuse to move. So it is necessary to change the configuration of the line protection devices [9].

\subsection{The Impact on the System Protection}

The impact on the system reliability of distributed power supply depends on the circumstances. It is advantageous to improve system reliability when distributed power supply serves as a backup power supply; When distributed power supply makes the parallel operation with distribution network, the impact on the system reliability depends on the control mode and the degree of coordination between different distributed power supplies.

\section{The Impact of Distributed Power Supply on the Net Loss}

The connection of distributed power supply to grid will change the original network distribution form. The line flow is no longer a one-way flow from the power supply to each load because of its magnitude and direction depending on the situation of distributed power supply connected to grid [10-13]. So the line loss is changed compared with the original network. Distributed power supply is generally connected to grid from the user side so that it will change the system load distribution. There are mainly three kinds of situation:

1) The power provided by the distributed power supply is less than the load of any node. At this situation, the introduction of distributed power supply can reduce all the line net loss in the distribution network;

2) The power provided by the distributed power supply is still less than the total system load but not the load of all nodes is more than the power provided by the distributed power. At this situation, the introduction of distributed power supply can still reduce all the line net loss in the distribution network but it may lead to an increase in certain network loss;

3) The power provided by the distributed power supply is more than the total system load but not the load of all nodes is less than the power provided by the distributed power. At this situation, the impact on the net loss of the distributed power supply needs to be 
discussed according to different situations. If $\mathrm{P}_{\mathrm{S}}<\mathrm{P}_{\mathrm{DG}}<2 \mathrm{P}_{\mathrm{S}}\left(\mathrm{P}_{\mathrm{DG}}\right.$ is the total power provided by the distributed power supply. $P_{S}$ is the total system load ), the impact on the net loss of the distributed power supply connected to grid is the same as the second situation. If $\mathrm{P}_{\mathrm{DG}}>2 \mathrm{P}_{\mathrm{S}}$, this will make the network loss increase. Thus, distributed generation may increase or decrease the net loss of the system. This is not only related to load but also closely to the distributed power supply capacity, specific location and the network topology.

\section{The Theoretical Analysis of Impact on the Net Loss}

Distribution network model is shown in Figure 1 and Figure 2. Figure 1 is the model without distributed generation connected to power system. Figure 2 is the model with distributed generation connected to power system.

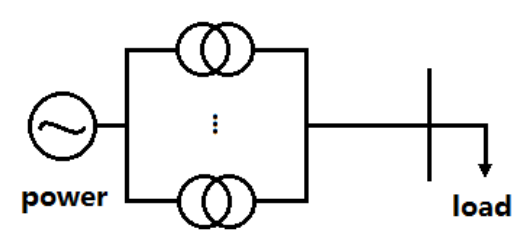

\section{Figure 1. Distribution Network without DG}

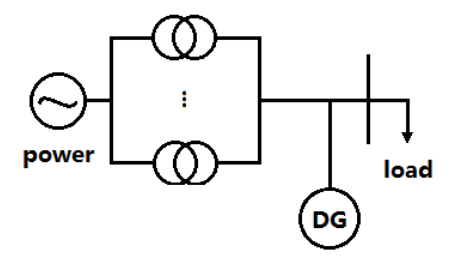

\section{Figure 2. Distribution Network with DG}

The total loss is the line power loss $L_{\text {line }}$ and transformer loss $L_{\text {trans }}$ in Figure 1 before putting in the ith distributed generation.

(1)

$$
L=L_{\text {line }}+L_{\text {trans }}
$$

The amount of change in net loss can be reflected in three parts after putting in the ith distributed generation.

a. Line loss between the power supply and distributed generation $L_{m i}$;

b. Line loss between the load and distributed generation $L_{n i}$;

c. Transformer loss $L_{\text {transi }}$.

Therefore, the total loss after putting the distributed generation is:

(2)

$$
L^{\prime}=L_{m i}+L_{n i}+L_{\text {transi }}
$$

\subsection{The Change Rate of Net Loss}

The change rate of net loss represents the changes of net loss degree after distributed 
generation connected to power system. It can be used to know the cost-sharing of the whole distribution network net loss on each distributed generation.

The network loss change rate of single distributed generation connected to power system is:

$$
C_{L i}=\frac{L_{i}-L_{i}^{\prime}}{L} \times 100 \%
$$

In the formula:

$C_{L i}$ is the network loss change rate of ith distributed generation connected to power system;

$L_{i}$ is the active power loss of the whole network when ith distributed generation stops running;

$L_{i}^{\prime}$ is the active power loss of the whole network when ith distributed generation runs.

The network loss change rate of all distributed generation connected to power system is:

$$
C_{L \Sigma}=\frac{L_{\Sigma}-L_{\Sigma}^{\prime}}{L_{\Sigma}} \times 100 \%
$$

(4)

In the formula:

$C_{L \Sigma}$ is the network loss change rate of all the distributed generation connected to power system;

$L_{\Sigma}$ is the active power loss of the whole network when all the distributed generation stops running;

$L_{\Sigma}^{\prime}$ is the active power loss of the whole network when all the distributed generation runs.

The change rate of net loss is the digital display of distributed generation influence degree to the whole network net loss. The change rate of net loss is the ratio of net loss change after distributed generation connected to power system to the net loss before distributed generation connected to power system. If the result is negative, the larger the absolute value of numerical value is, the more net loss is increased by distributed generation. The distributed generation needs to assume a greater proportion of loss allocation. If the result is positive, the larger the numerical value is, the more net loss is decreased by distributed generation. The influence degree of each distributed generation to the change of the whole network net loss can be judged by the change rate of net loss [14].

\subsection{The Allocation Rate of Net Loss}

The allocation rate of net loss represents share of net loss caused by distributed generation unit capacity after distributed generation connected to power system. It can be used to guide the active power generation plan of each distributed generation connected to power system.

The network loss allocation rate of single distributed generation connected to power system is: 


$$
H_{P i}=\frac{L_{i}-L_{i}^{\prime}}{G_{i}} \times 100 \%
$$

(5)

In the formula:

$H_{P i}$ is the network loss allocation rate of ith distributed generation connected to power system;

$L_{i}$ is the active power loss of the whole network when ith distributed generation stops running;

$L_{i}^{\prime}$ is the active power loss of the whole network when ith distributed generation runs;

$G_{i}$ is the active power provided by ith distributed generation.

The network loss allocation rate of all distributed generation connected to power system is:

(6)

$$
H_{p_{\Sigma}}=\frac{L_{\Sigma}-L_{\Sigma}^{\prime}}{G_{\Sigma}} \times 100 \%
$$

In the formula:

$H_{P \sum}$ is the network loss allocation rate of all the distributed generation connected to power system;

$L_{\Sigma}$ is the active power loss of the whole network when all the distributed generation stops running;

$L_{\Sigma}^{\prime}$ is the active power loss of the whole network when all the distributed generation runs;

$G_{\Sigma}$ is the active power provided by all the distributed generation.

The allocation rate of net loss represents share of net loss caused by distributed generation unit capacity after distributed generation connected to power system. If the result is negative, the larger the absolute value of numerical value is, the more active power loss increment is caused by distributed generation unit capacity. If the result is positive, that means distributed generation connected to power system promote the whole network net loss down.

\subsection{The Theoretical Analysis}

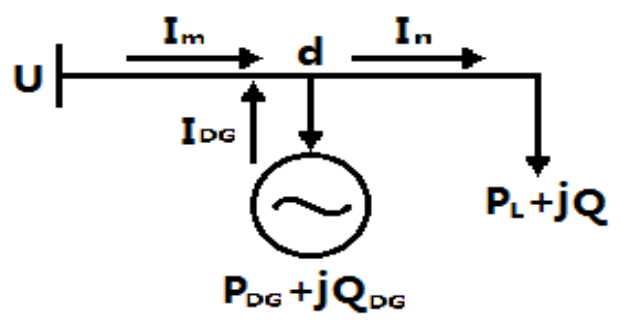

Figure 3. Simple Model of Distributed Generation Connected To Distribution Network

There is a simple model of distributed generation connected to distribution network 
shown in Figure 3. Suppose the value of voltage source is $U$ and the value of distributed power supply capacity is $P_{D G}+j Q_{D G}$.

When there is no distributed power supply connected at point $d$, the current flowing into the load is:

$$
I_{1}=\frac{P_{L}-j Q_{L}}{3 U}
$$

In this case the loss of the line is:

$$
L=\frac{R\left(P_{L}^{2}+Q_{L}^{2}\right)}{3 U^{2}}
$$

(8)

In the formula, $R$ is line resistance.

When distributed power supply with the capacity $P_{D G}+j Q_{D G}$ is connected to distribution network from point $\mathrm{d}$, the output current of distributed power supply is:

$$
I_{D G}=\frac{P_{D G}-j Q_{D G}}{3 U}
$$

The net loss on the feeder can be divided into two parts according to the position of distributed power supply connected to distribution network. The first part is the net loss between voltage source and distributed power supply. The second part is the net loss between the load and distributed power supply.

It can be know from Figure 3:

$$
I_{m}=I_{n}-I_{D G}
$$

$$
I_{n}=I_{1}
$$

The net loss of the first part:

$$
L_{m}=3 R_{m} I_{m}^{2}=\frac{R_{m}\left[\left(P_{L}-P_{D G}\right)^{2}+\left(Q_{L}-Q_{D G}\right)^{2}\right]}{3 U^{2}}
$$

$$
L_{m}=\frac{R_{m}\left(P_{L}^{2}+P_{D G}^{2}+Q_{L}^{2}+Q_{D G}^{2}-2 P_{L} P_{D G}-2 Q_{L} Q_{D G}\right)}{3 U^{2}}
$$

In the formula, $R_{m}$ is line resistance between voltage source and distributed power supply.

The current of the load side doesn't change before and after distributed generation connected to distribution network, so the net loss of the second part is:

$$
L_{n}=3 R_{n} I_{n}^{2}=\frac{R_{n}\left(P_{L}^{2}+Q_{L}^{2}\right)}{3 U^{2}}
$$

In the formula, $R_{n}$ is line resistance between load and distributed power supply. 
It can be known from the formula (13) and (14) that after distributed power supply connected the system net loss is:

$$
L^{\prime}=L_{m}+L_{n}
$$

It can be concluded that the influence amount of distributed power supply to the system net loss is:

$$
\Delta L=L-L^{\prime}=\frac{R_{m}\left(2 P_{L} P_{D G}+2 Q_{L} Q_{D G}-P_{D G}^{2}-Q_{D G}^{2}\right)}{3 U^{2}}
$$

$$
\Delta L=\frac{R_{m}}{3 U^{2}}\left[P_{L}^{2}+Q_{L}^{2}-\left(P_{L}-P_{D G}\right)^{2}-\left(Q_{L}-Q_{D G}\right)^{2}\right]
$$

Put the formula (17) into formula (3) and formula (5) separately.

$$
C_{L i}=\frac{R_{m}\left[P_{L}^{2}+Q_{L}^{2}-\left(P_{L}-P_{D G}\right)^{2}-\left(Q_{L}-Q_{D G}\right)^{2}\right]}{R\left(P_{L}^{2}+Q_{L}^{2}\right)}
$$

It can be known according to the formula (17), (18) and (19) that the impact of distributed power supply connected to distribution network on the net loss depends on its capacity connected to the grid, its location and its operation mode.

When the distributed power supply capacity is far less than the total load of system, $\Delta L$ can be approximately regarded as a monotonically decreasing line segment. This indicates the distributed power supply can reduce system net loss. If the location of distributed power supply access point is certain, $R_{m}$ can be certain too. At this situation, the larger distributed power capacity it is, the smaller system net loss it is; If the capacity of distributed power supply is certain, the father the location of access point is away from the bus, the smaller system net loss it is.

When the distributed power supply capacity is greater than a certain value, the net loss curve of different distributed power supply access locations change to $U$ type [15], so it is necessary to allocate distributed power supply in the right position near the bus, otherwise the net loss may increase, causing a voltage drop.

When the distributed power supply capacity is allocated in the front of the distribution network, the net loss curve is a parabola. If the active power output of distributed power supply is smaller than the load, it can reduce the net loss through increasing the active power output of distributed power supply. But with the capacity of distributed power supply increasing, the reduction degree of net loss tends to saturation; If the active power output of distributed power supply is greater than the load but smaller than the two times of the load, then increase the power output of the distributed power supply, although the total amount of net loss is still in the reduced state, the net loss reduction rate begins to decline. Because at this situation distributed power supply does not only provide power for the load but also output power to the upper level of the grid while the distribution network trend flows to the power reversely; If the active power output of distributed power supply is greater than the two times of the load, it will increase the net loss through increasing the active power output of distributed power supply. 


\section{Conclusion}

With the size and quantity of distributed power supply increasing in the nationwide, the problems of distributed power supply connected to distribution network also increase. The impact on the net loss is an important problem of them. This paper does the analysis of distributed power supply influences on the net loss after distributed power supply connected to the distribution network by the way of treating distributed power supply as the special load which can output active power. However, in the practice application, distributed power supply can not be treated simply as the load which can output active power. It is necessary to consider a wide range of content. The relatively complete model will be established in view of the theoretical analysis results above to make further analysis about the impact of distributed power supply connected to the distribution network on the net loss in the following time.

\section{Acknowledgements}

I would like to extend my sincere gratitude to my colleague Yan Zhao for his instructive advice and useful suggestions on my paper. I am grateful deeply of his help in the completion of this paper.

\section{References}

[1] K. J. Qian and Y. Yuan, "Relay", vol. 35, no. 25, (2007).

[2] C. S. Wang and P. Li, "Journal of Electric Power Science and Technology", vol. 23, no. 8, (2008).

[3] Z. X. Lu, C. X. Wang and Y. Min, "Automation of Electric Power Systems", vol. 31, no. 100, (2007).

[4] B. Zhao, C. S. Wang and J. H. Zhou, "Automation of Electric Power Systems", vol. 1, no. 125, (2014).

[5] W. S. Zhang and Y. Xu, "High-Technology \& Industrialization", vol. 1, no. 92, (2009).

[6] C. L. Gu and X. H. Leng, "Electric Switcher", vol. 52, no. 51, (2014).

[7] J. L. Cui and T. Q. Liu, "Modern Electric Power", vol. 24, no. 53, (2007).

[8] L. M. Zhang, W. Tang and Y. J. Zhao, "Power System Protection and Control", vol. 38, no. 132, (2010).

[9] Q. M. Cheng, Y. F. Wang and Y. M. Cheng, "Power System Protection and Control", vol. 39, no. 147, (2011).

[10] J. Q. Zhong, Z. G. Ye and Z. G. Lu, "Power System Protection and Control", vol. 40, no. 50, (2012).

[11] Y. Zhang and C. Wu, "Power System Protection and Control", vol. 38, no. 33, (2010).

[12] L. M. Zhang, W. Tang and Y. J. Zhao, "Power System Protection and Control, vol. 39, no. 91, (2011).

[13] C. H. Gao and X. Wu, "Jilin Electric Power", vol. 41, no. 17, (2013).

[14] Y. J. Zhang, W. F. Zhai and J. X. Lin, "Power System Protection and Control", vol. 39, no. 134, (2011).

[15] J. Li, "Journal of Shenyang Institute of Engineering (Natural Science)", vol. 5, no. 205, (2009).

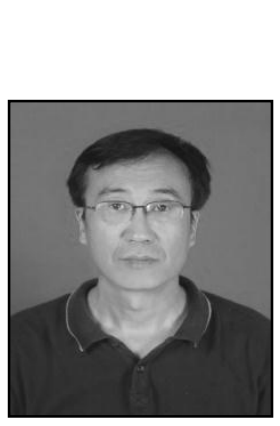

\section{Authors}

Shipeng Du, he received the B.E. degree in Northeast Dianli University, Jilin, China. He is currently an associate professor with the School of Renewable Energy, Shenyang Institute of Engineering, Shenyang. His current research interests include micro-grid control, sensor theory.

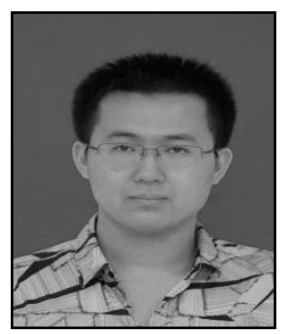

Qianzhi Shao, he received the B.E. degree in Energy and Power Engineering from Dalian University of Technology, Liaoning, China in 2012. He is currently working towards the Master in Electrical Engineering in Shenyang Institute of Engineering. 


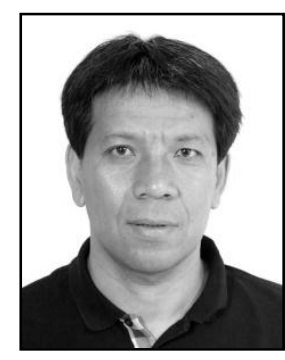

Gang Wang, he received his M.S. degree in Electronic Science from Shenyang Agricultural University, China, in 2011. He is currently a Ph.D. student in College Physics, Dalian University of Technology, China. His main research interests include pattern recognition, new material, and automatic control. 